\title{
Neo-deterministic seismic hazard scenarios for India-a preventive tool for disaster mitigation
}

\author{
Imtiyaz A. Parvez • Andrea Magrin • Franco Vaccari • \\ Ashish • Ramees R. Mir • Antonella Peresan • \\ Giuliano Francesco Panza
}

Received: 10 January 2017 / Accepted: 10 July 2017 / Published online: 8 August 2017

(C) Springer Science+Business Media B.V. 2017

\begin{abstract}
Current computational resources and physical knowledge of the seismic wave generation and propagation processes allow for reliable numerical and
\end{abstract}

I. A. Parvez $(\triangle) \cdot$ Ashish $\cdot$ R. R. Mir

CSIR Fourth Paradigm Institute (formerly CSIR C-MMACS),

NAL Belur Campus, Bangalore, India

e-mail: parvez@csir4pi.in

I. A. Parvez • R. R. Mir

Academy of Scientific and Innovative Research (AcSIR), CSIR-Fourth Paradigm Institute Campus, NAL Belur Campus, Bangalore, India

A. Magrin · F. Vaccari · A. Peresan

Department of Mathematics and Geosciences, University of Trieste, Trieste, Italy

A. Peresan

CRS-OGS, National Institute of Oceanography and Experimental Geophysics, Udine, Italy

G. F. Panza

Institute of Geophysics, China Earthquake Administration,

Beijing, China

G. F. Panza

International Seismic Safety Organization (ISSO), Arsita, Italy

G. F. Panza

Accademia Nazionale dei Lincei, Rome, Italy

Present Address:

A. Magrin

CRS-OGS, National Institute of Oceanography and Experimental Geophysics, Udine, Italy analytical models of waveform generation and propagation. From the simulation of ground motion, it is easy to extract the desired earthquake hazard parameters. Accordingly, a scenario-based approach to seismic hazard assessment has been developed, namely the neodeterministic seismic hazard assessment (NDSHA), which allows for a wide range of possible seismic sources to be used in the definition of reliable scenarios by means of realistic waveforms modelling. Such reliable and comprehensive characterization of expected earthquake ground motion is essential to improve building codes, particularly for the protection of critical infrastructures and for land use planning. Parvez et al. (Geophys J Int 155:489-508, 2003) published the first ever neo-deterministic seismic hazard map of India by computing synthetic seismograms with input data set consisting of structural models, seismogenic zones, focal mechanisms and earthquake catalogues. As described in Panza et al. (Adv Geophys 53:93-165, 2012), the NDSHA methodology evolved with respect to the original formulation used by Parvez et al. (Geophys J Int 155:489-508, 2003): the computer codes were improved to better fit the need of producing realistic ground shaking maps and ground shaking scenarios, at different scale levels, exploiting the most significant pertinent progresses in data acquisition and modelling. Accordingly, the present study supplies a revised NDSHA map for India. The seismic hazard, expressed in terms of maximum displacement (Dmax), maximum velocity (Vmax) and design ground acceleration (DGA), has been extracted from the synthetic signals and mapped on a regular grid over the studied territory. 
Keywords Seismic hazard · India · NDSHA · Disaster mitigation · Ground motion

\section{Introduction}

The Indian subcontinent is surrounded by the most seismically active areas of the world, including the Himalayan belt on the north, Kirthar and Sulaiman ranges on the west, Arakan Yoma ranges and Andaman Islands on the east (Fig. 1). Many devastating earthquakes inflicted heavy loss of life and considerable economic damage to the region (Fig. 2). Rapid urbanization, development of critical structures and lifelines, such as dams and nuclear power plants, industrialization of cities and the concentration of population, living or settling in hazardous areas, are all matters of growing concern. Thus, the recent social and economic development exposed to earthquake hazard implies in the future heavier loss of life and economic damage, unless reliable preventive actions are enforced following the rapid rise of interest about environment concerns, and

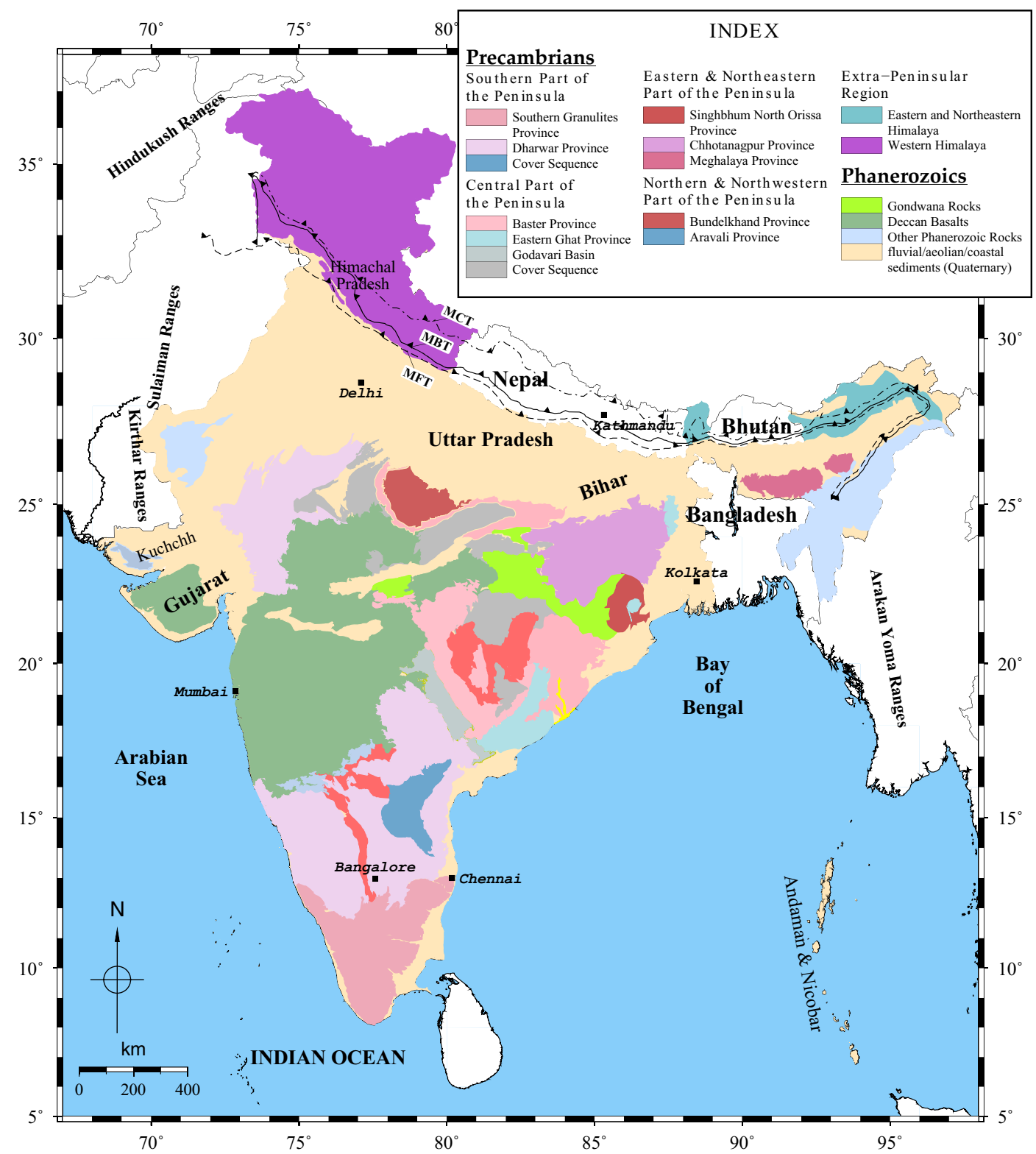

Fig. 1 Geological map of India and adjacent areas 


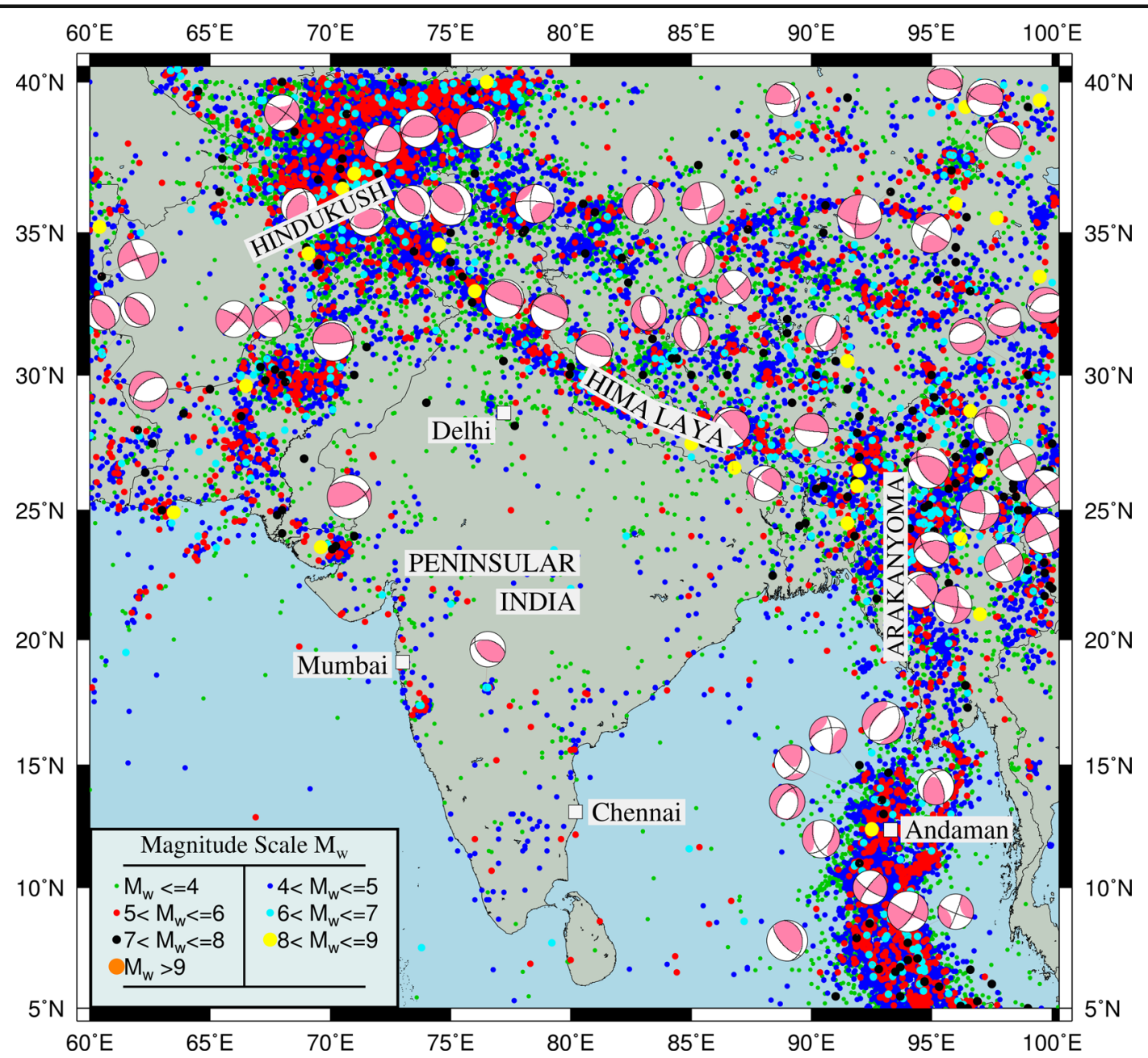

Fig. 2 Seismicity map of India and adjacent areas with focal mechanisms

increased official and public awareness about earthquake hazard in India.

Seismic hazard, by definition, describes a natural phenomenon associated with an earthquake, such as ground shaking, fault rupture, tsunami, liquefaction, rockfall and landslide. We do not discuss here all the available approaches used in seismic hazard, as it is beyond the purposes of the present work. However, they can be broadly classified as PSHA (probabilistic seismic hazard assessment) and DSHA (deterministic seismic hazard assessment) or, its enhancement, NDSHA (neodeterministic seismic hazard assessment). Many authors (e.g. Castaños and Lomnitz 2002; Klügel 2007; Wang 2011; Panza et al. 2014) expressed serious criticisms on the probabilistic method and evidenced some essential limits in the physical and mathematical models, as well as in other basic assumptions. Possible alternatives to
PSHA are discussed in the Topical Volume 168 of Pure and Applied Geophysics (Panza et al. 2011) and in Panza et al. (2012), where the NDSHA method is described in detail.

In order to mitigate the destructive impact of the earthquakes, the regional seismic hazard in India has been assessed using the neo-deterministic, multiscenario methodology based on the computation of synthetic seismograms. A more detailed definition of NDSHA, which is based on the possibility of efficiently computing realistic synthetic seismograms by the modal summation technique, is given by Panza et al. (2001). The neo-deterministic method describes seismic ground motion due to earthquakes based on modelling techniques of the seismic source process and of the propagation of seismic waves. This permits us to define a set of earthquake scenarios and to generate the associated 
synthetic seismograms without having to wait for strong events to occur. NDSHA can be applied at the regional scale, computing seismograms at the nodes of a grid with the desired spacing, or at the local scale, taking into account the source characteristics, the path and local geological and geotechnical conditions. Synthetic signals can be produced in a short time and at a very low cost/benefit ratio. Realistic synthetic seismograms are constructed using the available knowledge of the physical process of earthquake generation (source position and orientation of the focal mechanism), level of seismicity (distribution of maximum observed magnitude) and wave propagation in anelastic media. From these synthetic signals, engineering parameters can be extracted in order to assess the seismic hazard. Therefore, we can also estimate these parameters in those areas where very limited (or no) historical or instrumental information is available. As examples of the results that can be obtained, we show the maps of the distribution of maximum displacement (Dmax), maximum velocity (Vmax) and design ground acceleration (DGA) and the corresponding periods. NDSHA has been successfully tested worldwide (Panza et al. 1996, 1999, 2002; Alvarez et al. 1999; Aoudia et al. 2000; Bus et al. 2000; Markušić et al. 2000; Živčić et al. 2000; El-Sayed et al. 2001; Vaccari et al. 2001; Parvez et al. 2003; Zuccolo et al. 2011; Peresan and Panza 2012; Fasan et al. 2016) and has proved its efficiency, particularly for recent earthquakes (e.g. the Zemmouri-Boumerdes, Algeria, 2003 event; Gujarat, India, 2001 event; Emilia 2012 and Central Italy 2016 events), where the PSHA method has failed to predict the level of ground motion observed.

Parvez et al. (2003) published the first ever neodeterministic seismic hazard map of India by computing synthetic seismograms with input data set consisting of structural models, seismogenic zones, focal mechanisms and earthquake catalogues. Last decade has witnessed an increased activity in seismological experiments and provides more detailed and denser information of subsurface structures. As described in Panza et al. (2012), the NDSHA methodology evolved with respect to that applied in Parvez et al. (2003), and the computer codes were improved since their original implementation, to better fit the need of producing realistic ground shaking maps and ground shaking scenarios, at different scale levels. Now, there is a need to revise the existing deterministic hazard map (Parvez et al. 2003) with highresolution structural model, new focal mechanism data recently made available, extended source models, updated earthquake catalogue and inclusion of seismogenic nodes. Preliminary results about Gujarat region are included in Magrin et al. (2016). The present study is aimed to generate the second-generation NDSHA map for India using the updated inputs available to date.

\section{Input data}

The computation of realistic synthetic seismograms with the NDSHA technique greatly benefits from the knowledge of the source and propagation effects. Therefore, the input parameters describing the structural models and seismic sources must be properly defined for the study area, exploiting all significant available literature. In general, the input data include five main groups of parameters and these are (1) earthquake catalogue, (2) seismogenic zones, (3) fault plane solutions, (4) seismogenic nodes and (5) structural models. A brief description of each input parameter for the Indian subcontinent is given below.

\subsection{Earthquake catalogue}

Earthquake catalogues and databases are the most essential and important parametric information for any kind of seismic zoning or hazard studies. In the present study, the earthquake data set spanning the time interval from 25 to 2015 has been used. The Indian earthquake catalogue can chronologically be broadly divided into three groups: (1) pre-1900, based on pre-instrumental and historical macroseismic information; (2) the period 1900-1962, based on early instrumental data; and (3) post-1963, based on the WWSSN network and on modern instrumentation. We have used the databases from international agencies like NOAA, ISC, NEIC, CNSS and CMT and national agencies like IMD and NDMA and several published research papers to assemble our working catalogue. Some of the historical events have been re-assessed in terms of magnitude and location. In most cases, Ms and $\mathrm{Ml}$ are not present, and to be conservative, when more than one magnitude estimate is available, the maximum value is chosen. Empirical relations have been established between $\mathrm{Mw} \sim \mathrm{Ms}$, $\mathrm{Mw} \sim \mathrm{Mb}$ and $\mathrm{Mw} \sim \mathrm{Ml}$, and using these relations, a homogeneous catalogue in terms of $\mathrm{Mw}$ has been compiled. Figure 2 shows the seismicity map of Indian 
region in terms of Mw. In NDSHA, the catalogue completeness at moderate-to-low magnitudes is not necessary, contrary to PSHA, and just the potentially damaging events have to be considered. Therefore, we look at the spatial distribution of events with $\mathrm{Mw} \geq 5.0$.

\subsection{Seismogenic zones}

The seismogenic zones defined by Parvez et al. (2003) have been updated. They are very dense along the plate boundary, i.e. along the Kirthar Sulaiman, Hindukush, Himalaya, Arakan Yoma and Andaman (Fig. 1), whereas one can see gaps in seismicity in Peninsular India (Fig. 2). Though Peninsular India is considered relatively quiet seismically, still a dozen of seismogenic source zones have been defined there, based on the occurrence of some historical earthquakes. Similarly zones 703, 704 and 705, one of the largest, bring together earthquakes from Owen Fracture Zone (Makran subduction zone) and Sulaiman ranges and have been revised as the regions include strike slip, reverse slip and oblique slip motion, often resulting in shallow, destructive earthquakes. Now, there are 43 seismogenic zones defined for the Indian subcontinent (Fig. 3). One of the criteria driving this revision is the inclusion of new earthquakes with $\mathrm{Mw} \geq 5.0$ and focal depths less than $50 \mathrm{~km}$ that fall outside the seismogenic zones used by Parvez et al. (2003). Main changes are in Peninsular India: new seismogenic zones $(740,743,741)$ are introduced, and the geometry of others $(731,732,736)$ changes significantly. A new seismogenic zone was added in Northern India (742) and zone 718 was expanded. Figure 3 shows the set of seismogenic zones and the representative focal mechanisms for each zone.

\subsection{Fault plane solutions}

As for seismogenic zones, we have updated the focal mechanism database for each seismogenic zone defined by Parvez et al. (2003). One of the main criteria in the formation of the seismogenic zones is to examine the existence of similar focal mechanisms while defining the geometry of the zones and to identify a representative focal mechanism for each seismogenic zone. Focal mechanisms used in the present study are mainly taken from Harvard CMT Catalogues. However, published focal mechanism solutions by Fitch (1970), Molnar et al. (1973) and Chandra (1977, 1978) have been used for the large earthquakes that occurred before 1977 and

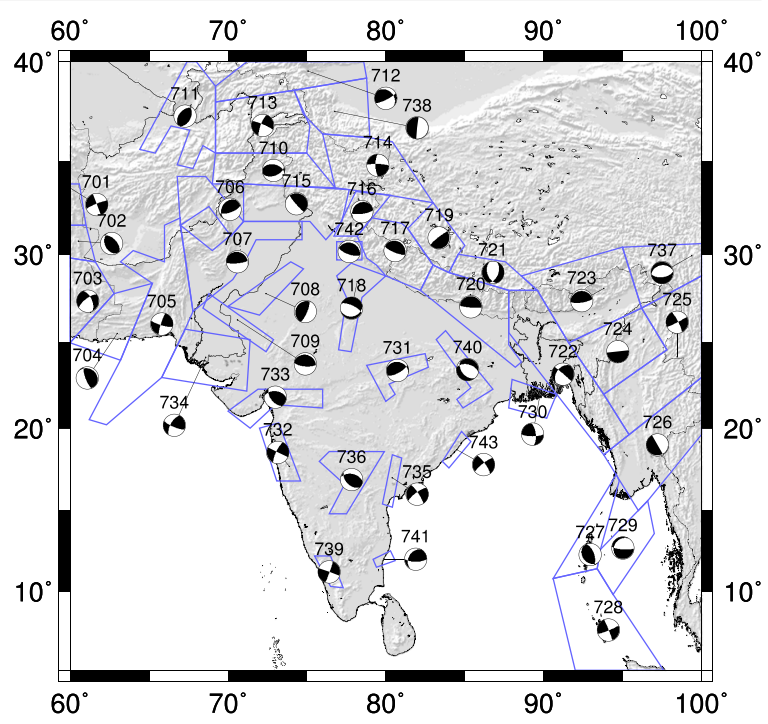

Fig. 3 The 43 seismogenic zones defined from the available information about geology, tectonics and historical seismicity of the region. The representative earthquake focal mechanism associated with each zone is shown, as well

for the Peninsular India events. A representative fault plane solution is defined for each seismogenic zone either looking at the mechanism associated with (a) the strongest event, (b) the best studied event, (c) the most frequent event or (d) the average mechanism obtained from the available moment tensor solutions (weighted by the scalar seismic moments). The entire investigated region is dominated by thrust and strike-slip faulting although normal-type faulting is present in a few zones (Fig. 3).

\subsection{Seismogenic nodes}

In addition to seismicity data, the flexibility of NDSHA permits incorporating the supplementary information about the possible location of strong earthquakes provided by morphostructural analysis, thus significantly reducing gaps in known seismicity, as reported in parametric catalogues (Zuccolo et al. 2011).

The methodology for the recognition of areas prone to large earthquakes includes two main steps. The first step is the identification of the morphostructural nodes using the morphostructural zoning method (Gelfand et al. 1972) that delineates a hierarchical block structure of the studied region, using tectonic and geological data, with special care to topography. The boundary zones between blocks are called lineaments. The nodes are formed at the intersections or junctions of two or more 
lineaments, characterized by a uniform set of morphostructural, topographic, geologic and geophysical parameters.

The second step is the classification of all mapped nodes into nodes where earthquakes with magnitude exceeding a certain threshold $\left(M_{\mathrm{N}}\right)$ are possible and nodes where only earthquakes with smaller magnitude may happen, using the pattern recognition algorithms CORA-3 (Gelfand et al. 1976; Gorshkov et al. 2003). This methodology has been applied to many seismic regions worldwide, and so far, $87 \%$ of the postpublication events occurred at the nodes recognized as prone to strong earthquakes (Keilis-Borok and Soloviev 2003 and references therein; Soloviev et al. 2014).

The recognition of earthquake prone areas has been carried out for Himalaya (Bhatia et al. 1992) for two magnitude thresholds, $M_{\mathrm{N}} \geq 6.5$ and $M_{\mathrm{N}} \geq 7.0$, and tested by Gorshkov et al. (2012). The nodes have been defined as circles of radius $R=50 \mathrm{~km}$ surrounding each point of intersection of lineaments (Fig. 4). A representative fault plane solution is defined for each seismogenic node in two ways: (1) where available from the average of focal mechanisms (weighted by the scalar seismic moments) of events from database described in Sect. 2.3 that fall inside the nodes and (2) using focal mechanisms of seismogenic zones that include the centre of the node.

\subsection{Structural model}

Layered anelastic models within which earthquake wave propagate are assembled representative of the average properties of the crust and upper mantle along the considered source site paths. In order to assemble a suitable structural model, available geophysical and geological information for the investigated territory has been considered after an extensive bibliographic search (Acton et al. 2010; Julià et al. 2009; Mandal 2006; Mitra et al. 2005, 2011; Murty et al. 2008; Srinagesh et al. 2011; Ravi Kumar et al. 2001; Ravi Kumar and Mohan 2005; Prasad et al. 2002; Tewari et al. 2009 and references therein). In this paper, the velocity structure given by Parvez et al. (2003) has been refined using a relatively higher resolution cellular model with the cells of $1^{\circ} \times 1^{\circ}$. Figure 5 shows the 387 cells, which include Nepal, Bhutan, Bangladesh and Andaman and Nicobar island regions, where the velocity model has been assembled. A similar study leading to cellular models in the Tibetan Plateau has been performed by Zhang et al. (2014).

Most of the cells have square shape except at the edges, where they are bounded at political boundaries or along the coastline (see Fig. 5). All velocity data were collected from broadband seismic studies, DSS studies and surface wave data. For each cell, two files were generated; one for the shape of the polygon and the other for the layer properties: thickness, density, Pwave velocity, S-wave velocity, Qp and Qs. The Southern India region is fairly well covered by receiver function experiments, while some other regions have quite poor data coverage or no coverage at all. In case of poor coverage, velocity models are copied from the cells, which fall in similar geological regions, while surface wave data, when available, have been used to obtain the layering for regions not covered by local studies. When different authors for the same cell have proposed different structural parameters, an educated average model has been prepared, giving more weight to the results of the recent publication obtained from
Fig. 4 Position of seismogenic nodes (blue circles) in Himalayan region from Gorshkov et al. (2012) and Bhathia et al. (1992)

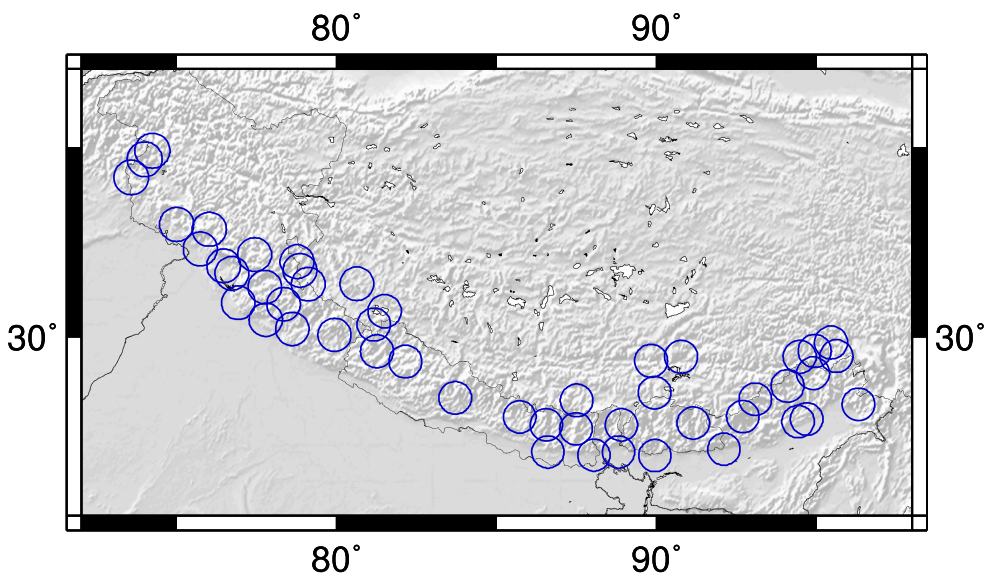




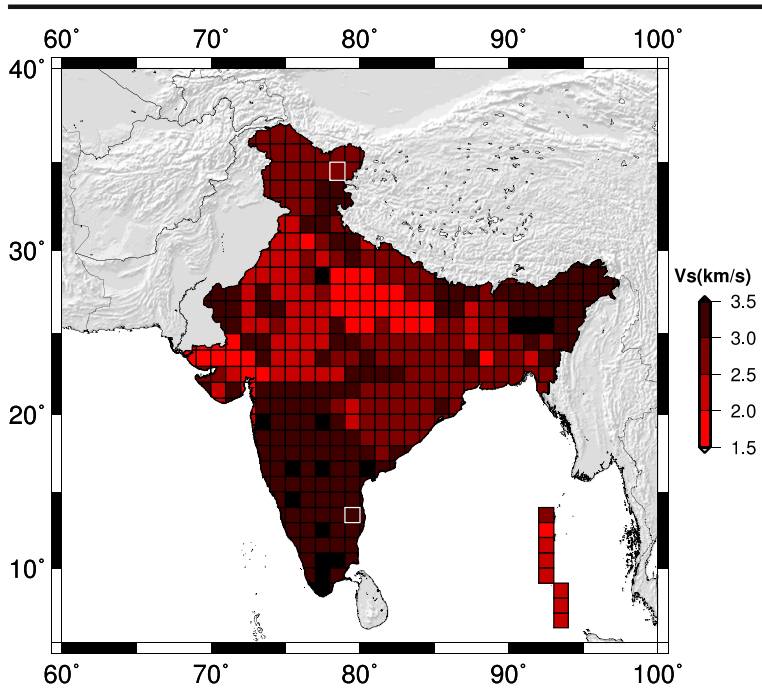

Fig. $5 \mathrm{Vs}$ in the topmost layer plotted for each cell. As an example, the layering of the cells with white borders is shown in Fig. 6

reliable high-resolution data. For those cells where updated velocity models are not available, the structural

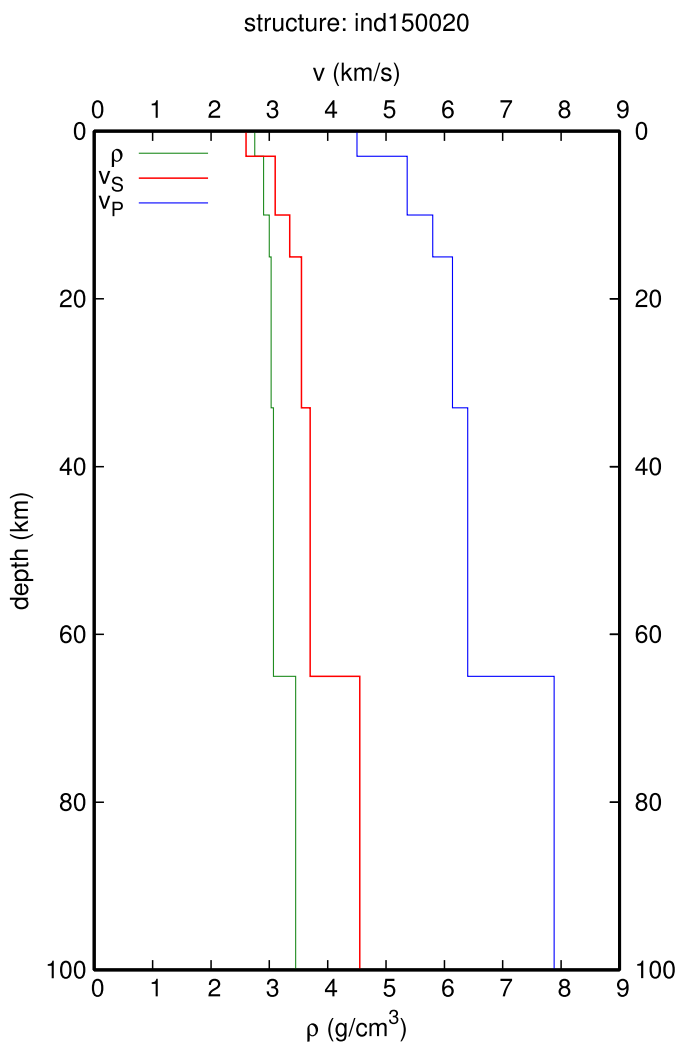

Fig. 6 Example of lithospheric structures associated with the cells with white borders in Fig. 5: cell 10 in Himalayan region and cell 356 in Peninsular India. Density, P- and S-wave velocities are model given by Parvez et al. (2003) has been adopted. Examples of the average structural model of two cells used in the computations are shown in Fig. 6, up to a depth of $100 \mathrm{~km}$. The legend in Fig. 5 gives the shear wave velocity (Vs) of the topmost layer for each cell.

The attenuation properties of the structure have been updated using the lithospheric attenuation tomography study across Eurasia by Gung and Romanowicz (2004) and the work by Mitchell et al. (2008). Figure 7 illustrates the Qs in the uppermost layer for each cell and evidences the high $Q$ values for the Indian shield as compared to the Himalayas and Northern India. This peculiarity may be related to the fact that the Indian shield is a deepseated, relatively undisturbed old continental lithosphere of probably high strength, whereas the Himalayan crust is surrounded by highly dislocated accretionary complexes, with relatively low strength, similar in their properties to usual tectonic environments (Parvez et al. 2001).

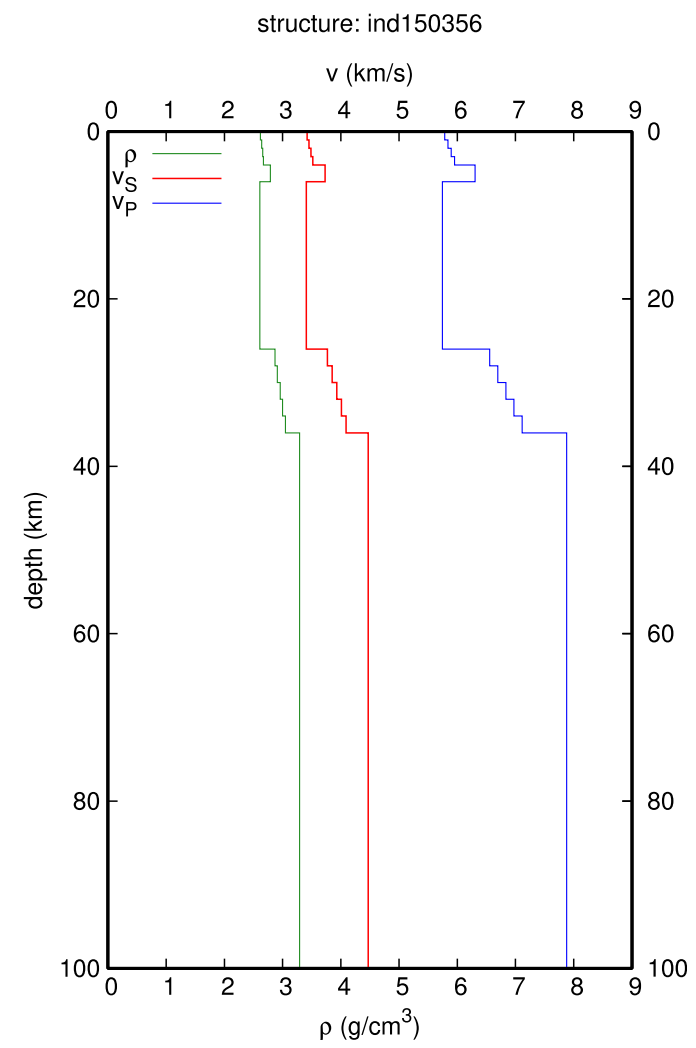

shown here for the uppermost $100 \mathrm{~km}$, but the complete structure reaches the depth of about $1000 \mathrm{~km}$. It is possible to see the different depths of Moho 


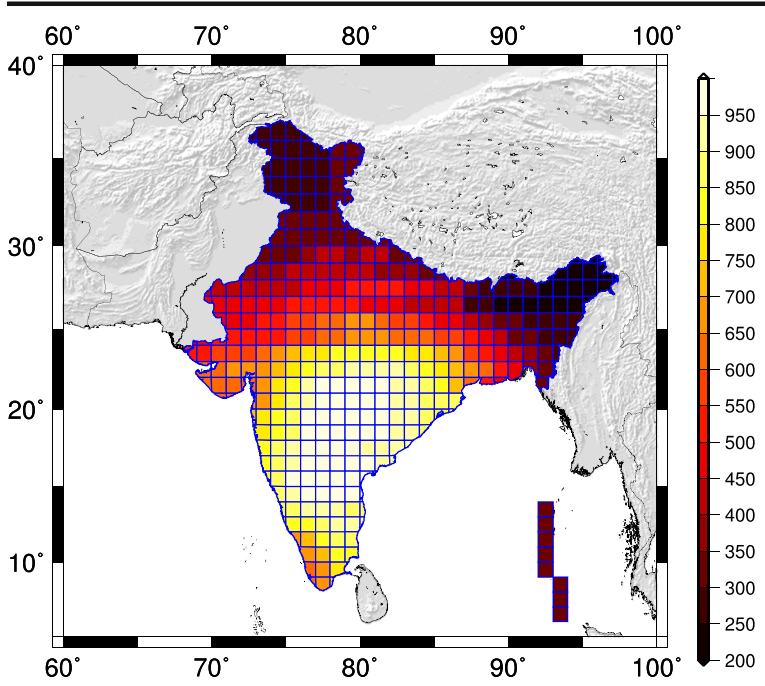

Fig. 7 Qs in the topmost layer plotted for each cell

\section{Methodology}

The procedure for the neo-deterministic seismic hazard assessment (NDSHA) (Panza et al. 2001, 2012) is based on the calculation of realistic synthetic seismograms (ground motion scenarios). In NDSHA, seismic hazard is defined as the envelope of the values of ground motion parameters considering a wide set of scenario earthquakes, including maximum credible earthquakes (MCE), calculated using the available physical knowledge on earthquake sources and wave propagation processes by means of physically rooted models. At the regional level, the ground shaking scenario is defined through the computation of synthetic seismograms generated from the set of potential sources distributed in the active seismogenic zones recognized in the study area.

In Fig. 8, we summarize the NDSHA methodology, as described in detail in Panza et al. (2001) and applied in Parvez et al. (2003), with inclusion of seismogenic nodes as described in Zuccolo et al. (2011). In the application of the NDSHA procedure at the regional scale, on account of the quality of the available data, the study area has been subdivided into a regular grid $0.2^{\circ} \times 0.2^{\circ}$. The seismic sources in NDSHA are placed at the centre of each cell of the grid, while the sites where signals are computed are placed at the nodes of the grid. Each source is characterized by a focal mechanism and a magnitude.

To define the source magnitudes, the NDSHA procedure makes use of information about the space distribution of large-magnitude earthquakes $(M>5)$, which can be defined from historical, instrumental and geological observations. In order to obtain a conservative distribution of the maximum observed magnitude over the Indian subcontinent, the seismicity map obtained from the earthquake catalogue, discretized in cells of the regular grid, is smoothed to partly account for the earthquake source dimensions, for catalogue incompleteness and for localization errors (Panza et al. 2001).

Only the sources that lie within a seismogenic zone or within a seismogenic node are selected amongst the ones defined during the smoothing process (Fig. 9).

Fig. 8 Flow chart of NDSHA methodology described in Sect. 3. In blue, the input data described in Sect. 2 that allow us to define structural model and seismic sources (in red) for which we compute the synthetic seismograms. The steps of the procedure described in Sect. 3 are in grey

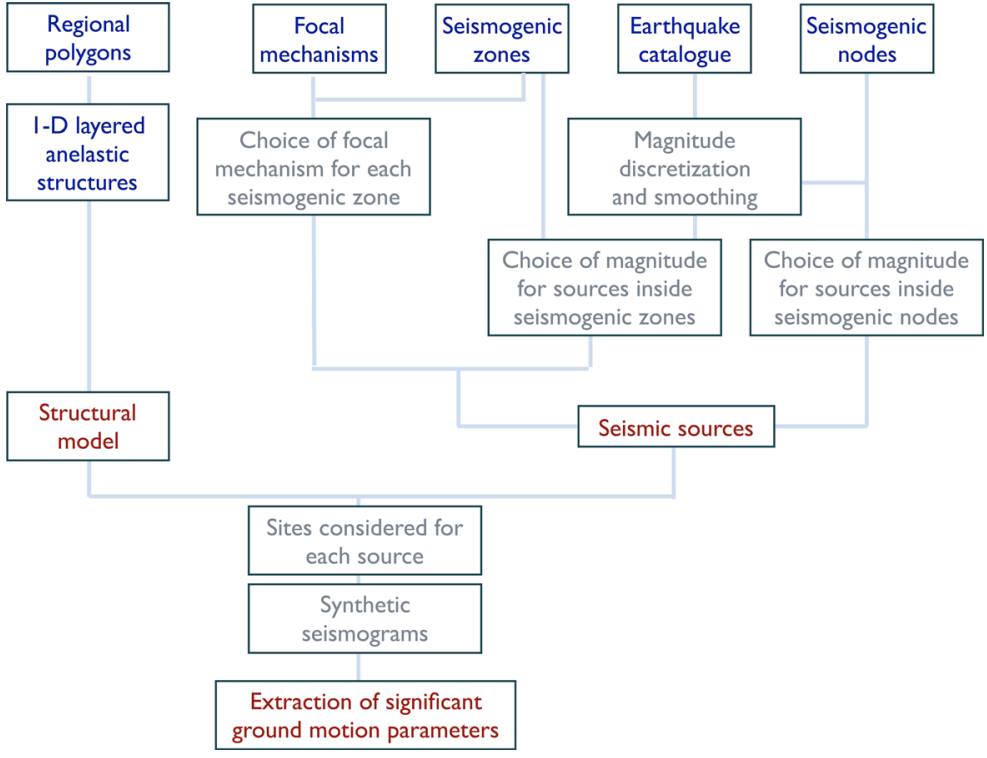




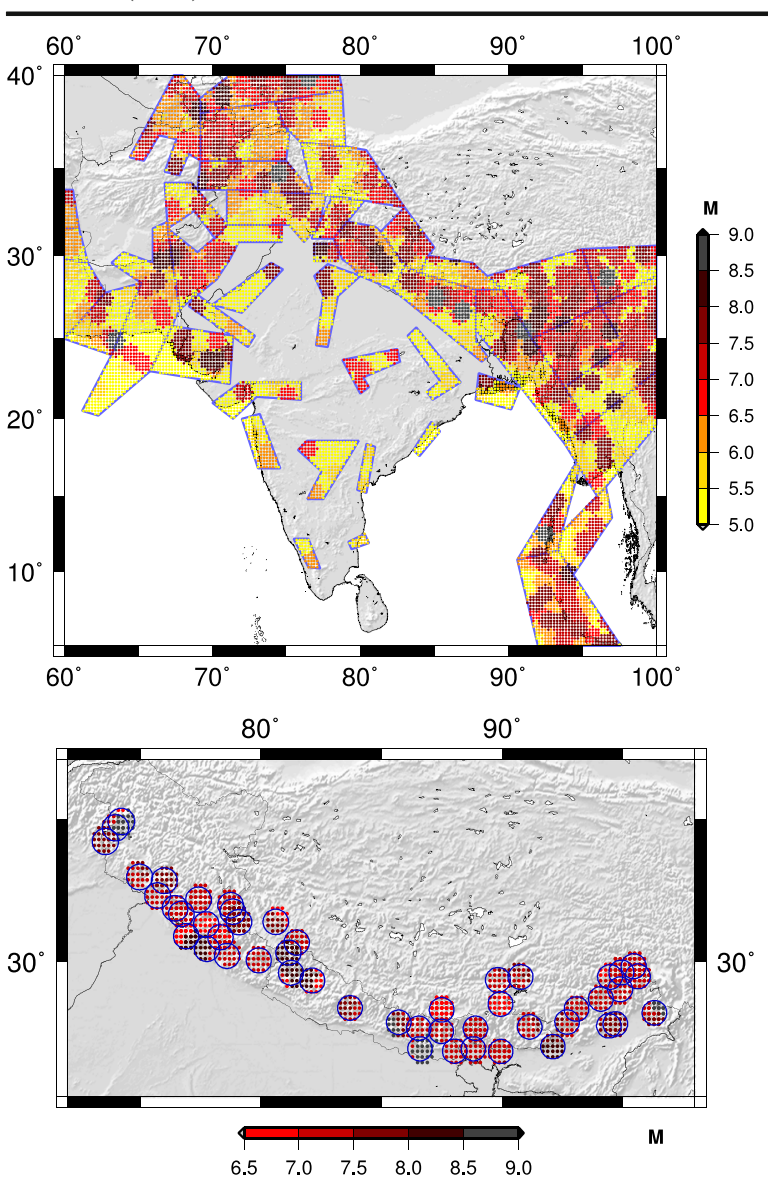

Fig. 9 Location and magnitude of the seismic sources used to generate the ground shaking maps: top: sources inside seismogenic zones of Fig. 3; bottom: sources inside seismogenic nodes of Fig. 4

Each source in this figure is described as a doublecouple point source. The strength of the source is determined as the maximum between a lower bound and the magnitude defined by the smoothing procedure. The lower bound for magnitude inside the seismogenic zones is 5 , that is conventionally (D'Amico et al. 1999) taken as the lower bound for the magnitude of damaging earthquakes. The lower bound of magnitude inside the seismogenic nodes is the magnitude threshold identified for that node by the morphostructural analysis. The orientation of the double-couple point source is the one representative of the parent seismogenic zone or seismogenic node. Hypocentral depth is taken as a function of magnitude (10 km for $M<7,15 \mathrm{~km}$ for $7 \leq M<8$ and $25 \mathrm{~km}$ for $M \geq 8$ ) in fairly good agreement with Doglioni et al. (2015).
The synthetic signals are computed for an upper frequency content of $1 \mathrm{~Hz}$, which is consistent with the level of knowledge about earthquake sources and regional structural model. If a source-site path crosses one or more boundaries between structural models, the site structural model is used along the entire path, since the site properties seem to have a large influence, as shown by Panza et al. (2001) for P-SV waves. To optimize the number of computed seismograms, the source-site distance is kept below an upper threshold, which is usually taken to be a function of the magnitude associated with the source. The horizontal component (P-SV radial and SH transverse) synthetic seismograms are first computed at each site for a seismic moment of $10^{-7} \mathrm{~N} \mathrm{~m}$ and then scaled to the magnitude of the earthquake using the moment-magnitude relation of Kanamori (1977). The finiteness of the source is accounted for by scaling the spectrum using a relatively simple scaling law. The horizontal components at each site are first rotated into a reference system common to the whole territory ( $\mathrm{N}-\mathrm{S}$ and $\mathrm{E}-\mathrm{W}$ directions), and then, the vector sum is calculated. The largest amplitude resulting signal, due to any of the surrounding sources, is selected and associated with that particular site.

For acceleration, the deterministic results are extended to frequencies higher than $1 \mathrm{~Hz}$ (i.e. the frequencies considered in the generation of the synthetic seismograms) by using design response spectra, for instance, Eurocode 8 (EC8 1993), which define the normalized elastic acceleration response spectrum of the ground motion, for 5\% critical damping, in such a way obtaining the design ground acceleration (DGA) (Panza et al. 1996). DGA is comparable to peak ground acceleration (PGA) since an infinitely rigid structure (i.e. a structure having a natural period of $0 \mathrm{~s}$ ) moves exactly like the ground (i.e. the maximum acceleration of the structure is the same as that of the ground, which is the PGA). This is why PGA has been used over the years to provide a convenient anchor point for the design spectra specified by various regulatory agencies. Moreover, DGA is practically equivalent to effective peak acceleration, which is defined as the average of the maximum ordinates of the elastic acceleration response spectra within the period range from 0.1 to $0.5 \mathrm{~s}$, divided by a standard factor of 2.5 , for $5 \%$ damping (Panza et al. 2003). At each node of the grid, not only the peak values are available, generated by the nearby earthquake sources, but also the full time series from which the peak values are extracted. 


\section{Computations}

As described in Panza et al. (2012), NDSHA methodology evolved with respect to that applied by Parvez et al. (2003) and the computer codes have been improved to better fit the need of efficiently producing realistic ground shaking maps and ground shaking scenarios, at different scale levels.

The computation of synthetic seismograms was enhanced by increasing the maximum length considered for the site-source paths and by using the discrete wave number technique (Pavlov 2009) for short paths, namely for epicentral distances less than, or comparable with, the source depth. Code optimization leads to a speedup in the computations by a factor of about 6 . This allowed us to consider, in the computations, the maximum source-receiver distance equal to $150,200,400$ and $800 \mathrm{~km}$, respectively, for $M<6,6 \leq M<7,7 \leq M<8$ and $M>8$ events and to guarantee that signals are computed up to distances where possible earthquake effects are significant.

In order to take into account the source extension, in the standard procedure, seismograms are scaled for the fault dimensions using a relatively simple spectral scaling law, with zero phase, called size-scaled point source (SSPS). In Parvez et al. (2003), two different scaling laws were used: the one proposed by Gusev (1983) as reported by Aki (1987) and a modified version, specific for East Himalayas sources. Here, we adopt a more realistic source model, in which phase spectrum accounts for the duration and other features of the rupture process, named by Parvez et al. (2011) sizeand time-scaled point source (STSPS). The extended source (ES) model is described in terms of a grid of subpoint sources (shortly subsources). The spectra of the subsource moment rate functions satisfy the condition to fit the reference spectral law and provide the basic elements necessary to describe realistically an ES. Their sum leads to a single source spectrum, representative of the entire space and time structure of the ES in far source condition (STSPS). A neutral directivity has been chosen in the computation of the synthetic seismograms, but the analysis of directivity effect can be made through parametric tests. As reference spectral law, we used the one given by Parvez et al. (2003) in the Appendix. The main effect of the introduction of STSPS source model is the natural increase in the duration of the synthetic seismograms and the reduction of peak amplitudes, especially for great magnitudes. In other words, the signals turn out to be more realistic than the ones by Parvez et al. (2003); however, in terms of damage potential, the results of this new modelling turn out to be not much different since the longer duration of the ground shaking obtained with the STSPS model can compensate for the decreased peak value.

\section{Results}

The maps of seismic hazard obtained for the whole India are shown in Fig. 10 for displacement, velocity and DGA. The highest peaks are obtained in northeast India, eastern Nepal and part of Gujarat with displacement and velocity falling in the range $30-60 \mathrm{~cm}$ and 60 $120 \mathrm{~cm} \mathrm{~s}^{-1}$, respectively. In other parts of the region, such as the central and western Himalayas, western Uttar Pradesh, Himachal Pradesh, western and central Nepal and some parts of the Gujarat state and Northeastern India, the maximum velocity is up to $60 \mathrm{~cm} \mathrm{~s}^{-1}$ and the maximum displacement is $\sim 30 \mathrm{~cm}$. In the area of Andaman and Nicobar, some parts have the maximum velocity up to $120 \mathrm{~cm} \mathrm{~s}^{-1}$, but the majority of cells fall in the range $30-60 \mathrm{~cm} \mathrm{~s}^{-1}$. Similarly, the displacement is in the range $15-30 \mathrm{~cm}$ and reaches the range of 30-60 cm in north Andaman.

The maximum values of DGA (above $0.6 \mathrm{~g}$ ) are in Gujarat, Northern India, central and eastern Nepal, epicentral zone of the great Assam earthquakes of 1897 and 1950 and Andaman islands. Lower values (0.3-0.6 g) are in Western Nepal, Northeastern India and Bangladesh.

The three metropolitan and biggest cities of India, with relevant industrial and economical importance, namely Delhi, Mumbai and Kolkata, lie in the hazardous zones of the DGA map. The most severe hazard is in Kolkata and its surroundings, where the DGA estimate is between 0.3 and $0.6 \mathrm{~g}$, followed by Delhi $(0.15-$ $0.3 \mathrm{~g}$ ), while in Mumbai, estimates are between 0.04 and $0.08 \mathrm{~g}$. The DGA estimates in Peninsular India are less than $0.15 \mathrm{~g}$ with maximum values $(0.08-0.15 \mathrm{~g})$ south of Mumbai.

We tested the effect of use of seismogenic nodes by comparing hazard maps of Fig. 10 with maps computed without seismogenic nodes. The increasing of magnitude of sources produces an increase of expected ground motion only in a few points. The effect of nodes is lower than what happens in Italy (see Zuccolo et al. 2011) because of the magnitudes of historical events in 

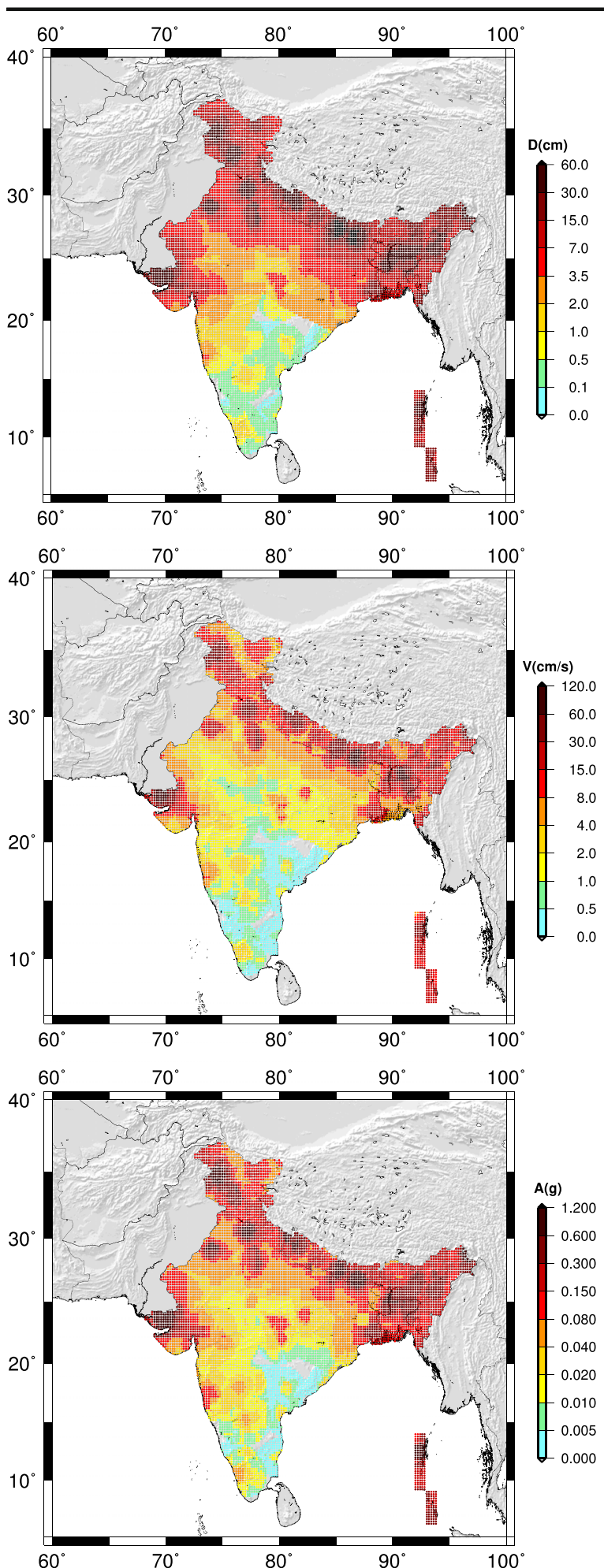

Fig. 10 Peak Ground Displacement (PGD) on top, Peak Ground Velocity (PGV) in middle and maximum DGA in the bottom
Himalayan region (up to 8.8) that is bigger than magnitude of nodes $\left(M_{\mathrm{N}}=6.5\right.$ or $\left.M_{\mathrm{N}}=7.0\right)$ : the ground motion maps are dominated by the effect of the biggest events.

\section{Comparison with maps of Parvez et al. (2003)}

Changes in the input definition and in some parts of the procedure with respect to Parvez et al. (2003) produce several differences in the new hazard maps, even if the general hazard pattern remains persistent. The distribution of sources (shown in Fig. 9) changed with respect to the one used in Parvez et al. (2003), due to differences in shape and location of the seismogenic zones, especially in Peninsular India. In addition, with the new catalogue source, magnitudes are generally greater than those used in the old computations.

Another added value of this study is to include the seismogenic nodes formed at the intersections or junctions of two or more lineaments, characterized by a uniform set of morphostructural, topographic, geologic and geophysical parameters (Fig. 4). The changes in the absolute values of PGV and DGA due to the computations from the seismogenic nodes are illustrated in Fig. 11.

The comparison of PGV maps is shown in Fig. 12. Only the sites where there is a change of at least $1^{\circ}$ of intensity, corresponding to about a factor of 2 in the peak value (Cancani 1904; Panza et al. 2001), are mapped. The areas showing the largest increase are distributed around seismogenic zone number 708, in Uttar Pradesh, in Western Nepal and in Northern coast of Bengala Gulf. Lower PGV values are concentrated in Northeastern India and around seismogenic zones 731 and 735 . The new structural model explains some of these changes, for example, the decrease of PGV values in Northeastern India, due to higher values of Vs in shallower layers. Other changes can be associated with variations in the source properties (focal mechanism and the adoption of the STSPS model).

A noticeable difference with respect to the maps by Parvez et al. (2003) is the increased number of grid nodes where the hazard estimate is provided. Considering only the common areas where the hazard was estimated (see Fig. 3 in Parvez et al. 2003 and Fig. 5 in the present work), we have now 8052 grid points instead of 3796. This is due to the extended maximum epicentral distance allowed in the new computations. It 


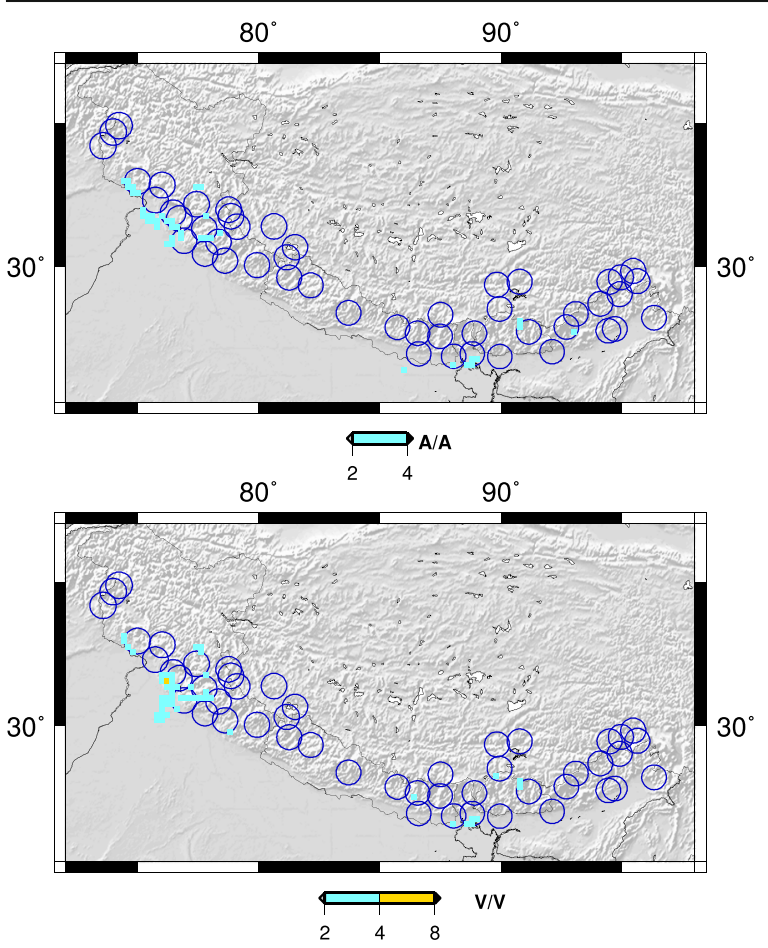

Fig. 11 Increase of DGA (top) and PGV (bottom) due to use of nodes

now happens that in some regions, hazard is controlled by far sources with great magnitude, rather than by smaller local earthquakes. If we now concentrate on the points in common between the two sets, about $50 \%$ of the values are compatible between old and new maps (ratio between 1:2 and 2 in Table 1). For all considered ground motion parameters (displacement, velocity and DGA), the hazard increase is more evident where Parvez et al. (2003) obtained the lower values.

\section{Comparison with observed intensities}

In order to test the quality of the NDSHA results, the DGA values of the old (Parvez et al. 2003) and new maps (Fig. 10) have been converted to intensities using the relation between acceleration and EMS intensity of Lliboutry (2000) and compared with the observed intensities reported in the European Macroseismic Scale (EMS) by Martin and Szeliga (2010). The relation between acceleration and intensity reported by Lliboutry (2000) is compatible with other similar relations (e.g. Medvedev 1977), taking account for the difference in the used intensity scales. Neo-deterministic maps aim to estimate the maximum possible shaking; therefore, underestimation of maximum intensity is a failure of the map. It is important to underline that in this paper, we present maps computed at bedrock, whereas the reported intensities can include substantial effects of local amplifications.

Martin and Szeliga (2010) published a unified catalogue of felt intensity data for 570 earthquakes in India from 1636 to 2009. Most of the reported earthquakes (more than 90\%) occurred in the past two centuries. The catalogue contains the latitude, longitude and location of each felt report and its inferred intensity, evaluated on the base of the EMS-98. As observed by Martin and Szeliga (2010), the completeness of the catalogue is
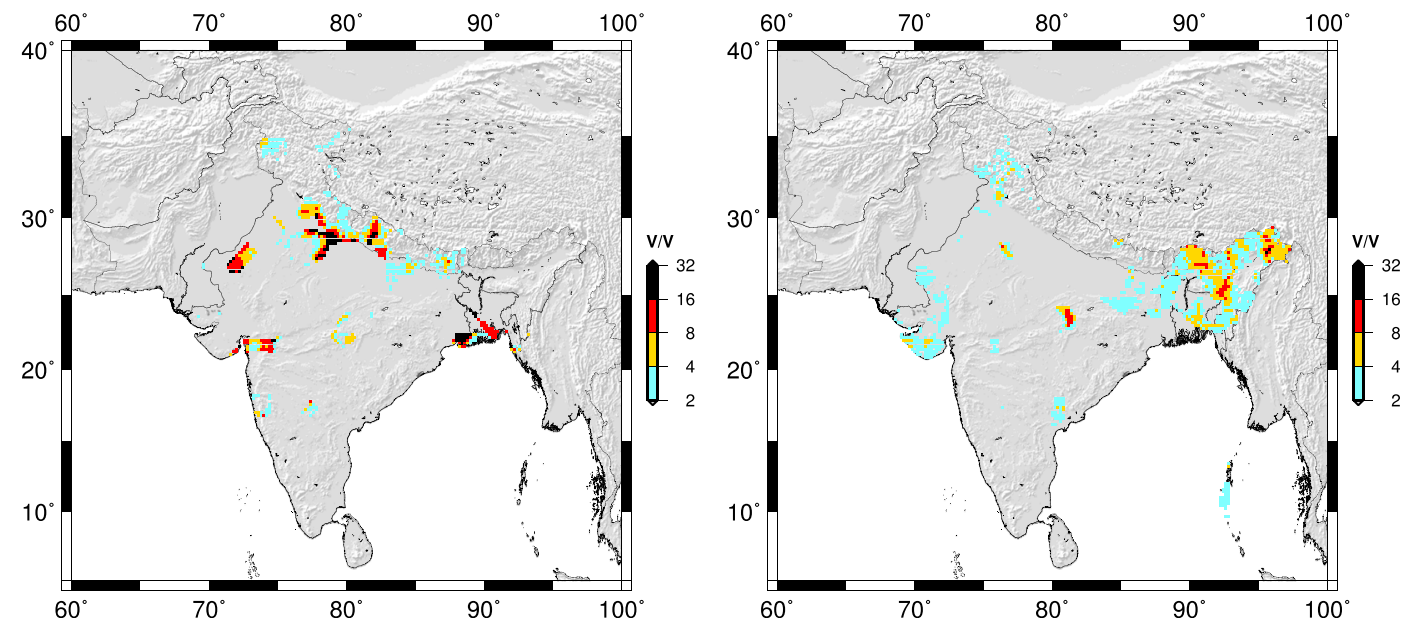

Fig. 12 Ratios between PGV map from Parvez et al. (2003) and PGV map of Fig. 10 (computed in common points). Map on the left shows where new values are greater than older; the right one shows where the new values are lower than older 


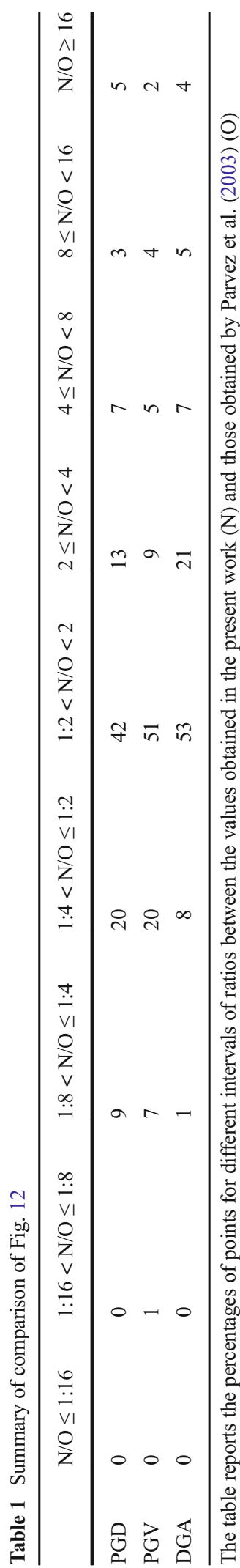

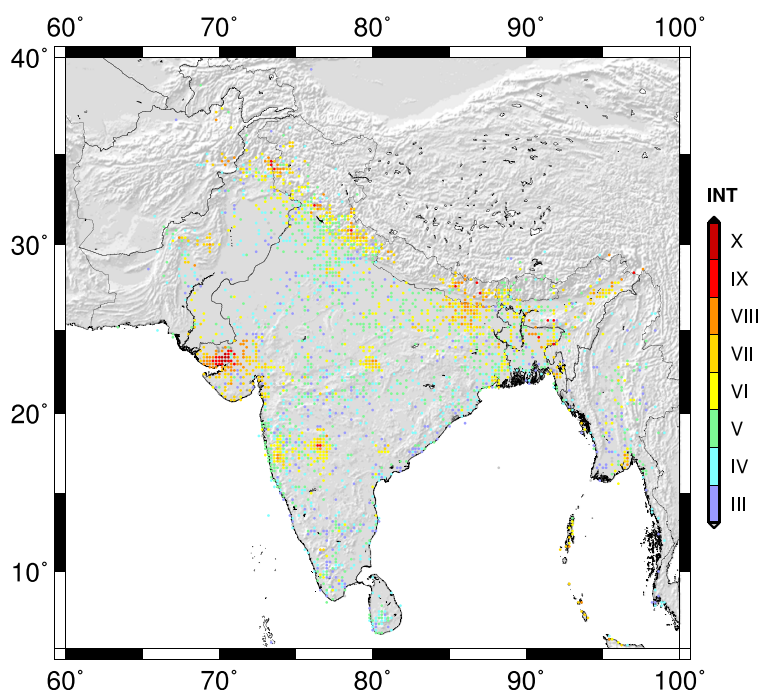

Fig. 13 Spatial distribution of maximum observed intensities in EMS scale $\left(I_{\text {MAX }}\right)$ taken from Martin and Szeliga (2010), discretized into cells of $0.2^{\circ} \times 0.2^{\circ}$

conditioned by some factors: density of population, propensity of a population to permanently record the perception of shaking or damage and types of exposed building. They emphasize that their catalogue is complete only for $M>8$ in the Indian subcontinent since 1800.

We computed the spatial distribution of maximum observed intensities from Martin and Szeliga (2010) discretized on the same regular $0.2^{\circ} \times 0.2^{\circ}$ mesh used for the modelling (Fig. 13). Then, we compared the maximum observed intensities ( MAX $\left._{\mathrm{MAX}}\right)$ with the intensities computed from DGA values of the old (Parvez et al. 2003) and new maps (Fig. 10) converted to intensities $\left(I_{\mathrm{DGA}}\right)$ using the relation between acceleration and EMS intensity of Lliboutry (2000). We can see that where observations are available, the modelled intensities are rarely exceeded by maximum observed intensities (Fig. 14 and Table 2). Underestimations of intensities equal or greater than $2^{\circ}$ (red and orange points) are only present in central and southern India for the new map, whereas for the old results, they can be found also in Northern India, Gujarat and north-eastern India as well. For both models, the relevant underestimations are obtained in the Latur region. From Table 2, we can say that accordingly with this comparison, the performance of new map overcomes the old one. For the new map, the underestimation of $I_{\mathrm{MAX}}$ is greater than $1^{\circ}$ of intensity only in $2 \%$ of the cells for $I_{\text {MAX }}$ between VI and VIII and in 7\% 


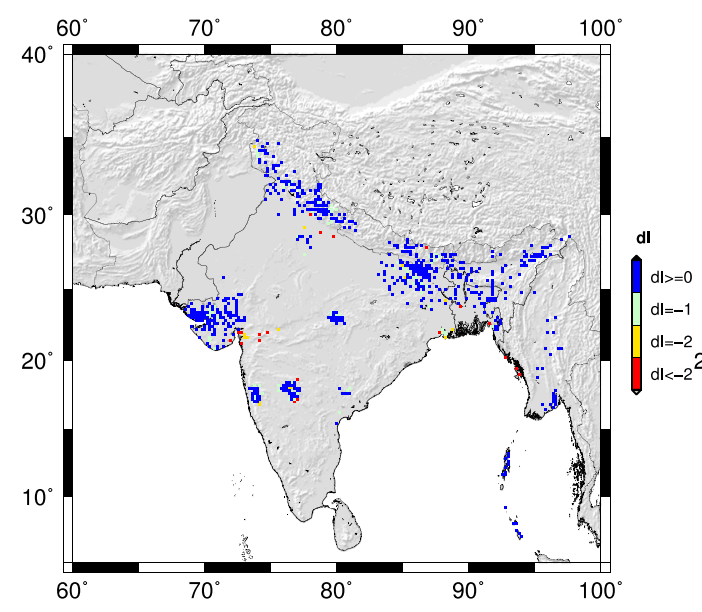

Fig. 14 Distribution of the difference between intensities converted from DGA $\left(I_{\mathrm{DGA}}\right)$ and observed intensities $I_{\mathrm{MAX}}$ (for $I_{\mathrm{MAX}} \geq \mathrm{VI}$ ) (as in Fig. 13): $d I=I_{\mathrm{DGA}}-I_{\mathrm{MAX}}$. DGA values used to compute intensities are taken from Parvez et al. (2003) for the map on the

of the cells for $I_{\mathrm{MAX}}=\mathrm{IX}$ and there is no underestimation for $I_{\mathrm{MAX}}=\mathrm{X}$.

\section{April 2015 Nepal earthquake}

A great devastating earthquake, followed by a series of $M>6$ aftershocks, including a $M=7.3$ event on May 12 , 2015, shook Nepal on April 25, 2015, with $M \mathrm{w}=7.8$ and $I_{\mathrm{MAX}}=$ IX that killed 8964 people $(23,447$ the injured ones). The earthquake occurred $80 \mathrm{~km}$ northwest of the Nepalese capital, Kathmandu, nucleated $\sim 80$ km northwest of Kathmandu and ruptured a 140-km-long segment of the fault with a hypocentral depth of $\sim 15 \mathrm{~km}$ and a dip of 7-

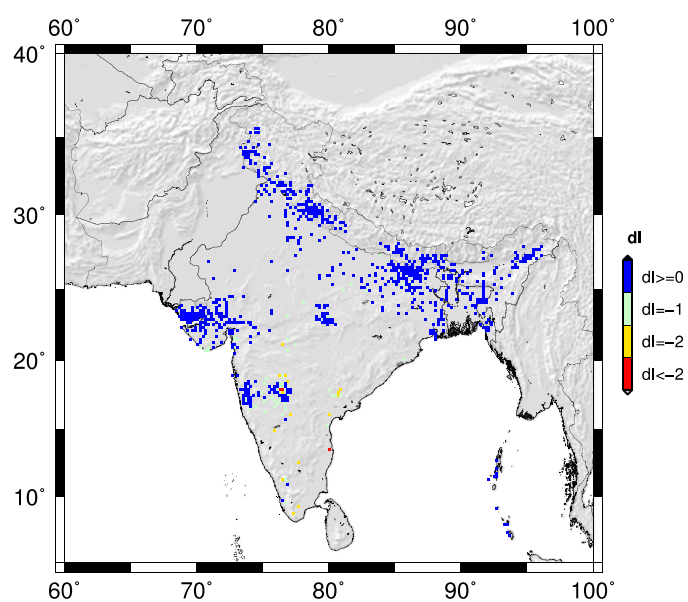

left and from the present study for the map on the right. The dominance of blue dots indicates that $I_{\mathrm{DGA}} \geq I_{\mathrm{MAX}}$ for most of the sites

$12^{\circ}$. According to USGS, the location, size and focal mechanism of the earthquake are consistent with its occurrence on the main subduction thrust interface between the India and Eurasia plates. This earthquake is not a surprise amongst the scientific community, as it is well known that the Indian plate is continuing to dive below the Eurasian plate at a velocity of about $5 \mathrm{~cm}_{\text {year }}{ }^{-1}$.

As pointed out by Dixit et al. (2015), strong-motion monitoring in Nepal has remained limited, so instrumental data are lacking in the near-source region (Hough 2015). The nearest available instrumental records of the mainshock are the few from Kathmandu area: a conventional strong-motion instrument installed at a US Embassy facility (KATNP) (Galetzka et al. 2015; Dixit

Table 2 Summary of comparison in Fig. 14

\begin{tabular}{lllllll}
\hline & $I_{\text {DGA }}$ computed from Parvez et al. (2003) & \multicolumn{4}{c}{$I_{\text {DGA }}$ computed from present study } \\
\hline$I_{\text {MAX }}$ & No. of cells & $d I \geq 0$ & $d I \geq-1$ & No. of cells & $d I \geq 0$ & $d I \geq-1$ \\
VI & 300 & 90 & 96 & 383 & 91 & 98 \\
VII & 250 & 83 & 94 & 260 & 89 & 98 \\
VIII & 109 & 79 & 95 & 103 & 90 & 98 \\
IX & 27 & 74 & 89 & 28 & 86 & 93 \\
X & 6 & 17 & 100 & 6 & 100 & 100 \\
\hline
\end{tabular}

As in Fig. 14, $d I=I_{\mathrm{DGA}}-I_{\mathrm{MAX}}$, where $I_{\mathrm{DGA}}$ means "intensity converted from DGA", $I_{\mathrm{MAX}}$ means "maximum observed intensity" and "No. of cells" is the number of cell where the value of maximum observed intensity is equal to $I_{\text {MAx }}$ and the DGA map reports a value. The table reports percentages of cells where $d I \geq 0$ and the percentages of cells where $d I \geq-1$. The total number of cells for each value of intensity is different between the two comparisons because of the different areas covered by maps of Parvez et al. (2003) and the maps of the present study 
et al. 2015), an accelerometer installed in the premises of the Department of Mines and Geology (DMG) in Lainchaur (Bhattarai et al. 2015) and a low-cost accelerometer (Dixit et al. 2015). The ground motion is dominated by long periods, due to the character of the source radiation combined with long-period basin effect (Galetzka et al. 2015). The hazard maps of this study (Fig. 10) give, for the grid point nearest to KATNP and DMG stations, the value of $30-60 \mathrm{~cm} \mathrm{~s}^{-1}$ for PGV and 0.6-1.2 $\mathrm{g}$ for DGA. The recorded PGA at KATNP and DMG stations is significantly lower, $\sim 0.16$ and $\sim 0.20 \mathrm{~g}$, respectively, whereas $\mathrm{PGV}$ is greater $\left(107 \mathrm{~cm} \mathrm{~s}^{-1}\right)$ at KATNP or equal $\left(58 \mathrm{~cm} \mathrm{~s}^{-1}\right)$ at DMG. While the discrepancy in acceleration values, though conservative, requires detailed ad hoc investigation, the underestimation of PGV value of KATNP can be well justified by longperiod effects discussed by Galetzka et al. (2015).

Because of the lack of instrumental data in the nearsource region, the only reasonable comparison with our hazard maps is supplied by the macroseismic data from Martin et al. (2015). The updated earthquake catalogue used to produce the hazard maps shown in Fig. 10 obviously includes the April-May 2015 sequence; therefore, to test the stability of NDSHA results, a DGA map has been produced removing from the catalogue the events of this sequence. We follow a procedure similar to that described in Sect. 7: from the macroseismic data of Martin et al. (2015), we computed $I_{\mathrm{MAX}}$ on the regular $0.2^{\circ} \times 0.2^{\circ}$ mesh used for the modelling and we converted DGA values into $I_{\text {DGA. }}$. From this comparison, we can say that $I_{\text {MAX }}$ linked with damage never exceeds $I_{\mathrm{DGA}}$; therefore, DGA values provide a cautious estimate of hazard even when the sequence is excluded. On the other hand, the inclusion of the 2015 sequence increases ground motion values only in a few points and provides a validation of the general ground shaking prediction capabilities of NDSHA.

\section{Conclusions}

Realistic synthetic seismograms have been computed for India using NDSHA to provide a powerful and economically valid robust scientific tool for seismic zonation and hazard assessment. Unlike other methods for estimating seismic hazard, the advantage of this approach lies in its ability to directly to account for the effects of source mechanism and wave propagation on the modelled ground shaking.
With respect to the work by Parvez et al. (2003), the structural model for the entire India has been redefined at a resolution of $1^{\circ} \times 1^{\circ}$, amounting to 387 cellular structures; the earthquake catalogue and the seismogenic zones have been updated and a more realistic source model, the size and time-scaled point source (STSPS), has been adopted in the computations.

The seismic hazard, expressed in terms of maximum displacement (Dmax), maximum velocity (Vmax) and design ground acceleration (DGA), has been extracted from the synthetic seismograms and mapped on a regular grid of $0.2^{\circ} \times 0.2^{\circ}$ over the entire country. The highest seismic hazard, expressed in terms of DGA (in the range of $0.6-1.2 \mathrm{~g}$ ), is mainly distributed in western Himalayas and Central Himalayas along the epicentral zone of Bihar Nepal earthquake, part of NE India and Gujarat (Kachchh region). A similar pattern has been found in peak velocities and peak displacements in the same areas.

We have also compared our results with the maximum observed intensities reported in EMS scale by Martin and Szeliga (2010). We can see that where observations are available, the modelled intensities are rarely exceeded by maximum observed intensities.

We believe that the robust results, well consistent with the information content of the available data (Panza et al. 2013), presented here contribute to a better understanding of the seismic hazard in India and neighbouring areas. They should also be used to update the building code IS 1893 of the Bureau of Indian Standards. Furthermore, our multidisciplinary approach may help those seismic and civil engineers who wish to undertake comprehensive and detailed studies of earthquake hazard especially in the eastern Himalayan region, eastern and western India and some big cities such as Delhi, Mumbai and Kolkata.

Acknowledgements The research presented in this paper benefited from financial support by Regione Autonoma Friuli Venezia Giulia (Italy) in the framework of cooperation activities for development and international partnership (Progetti Quadro, L.R. 19/2000). I A Parvez, Ashish and R R Mir also acknowledge ARiEES project of CSIR and thank the head, CSIR 4PI, for consistent support and encouragement.

\section{References}

Acton CE, Mitra S, Priestley K, Gaur VK (2010) Crustal structure of the Darjeeling, Sikkim Himalaya and southern Tibet. Geophys J Int 184:829-852. doi:10.1111/j.1365-246 X.2010.04868.x 
Aki K (1987) Strong motion seismology, in strong ground motion seismology, NATO ASI Series C, Mathematical and Physical Science, 204:3-39, eds Erdik, M. \& Toksoz, M., Reidel, Dordrecht

Alvarez L, Vaccari F, Panza GF (1999) Deterministic seismic zoning of eastern Cuba. Pure Appl Geophys 156:469-486 ISSN: 0033-4553

Aoudia A, Vaccari F, Suhadolc P, Meghraoui M (2000) Seismogenic potential and earthquake hazard assessment in the Tell Atlas of Algeria. J Seismol 4:79-88

Bhatia SC, Chetty TRK, Filimonov MB, Gorshkov AI, Rantsman EY, Rao MN (1992) Identification of potential areas for the occurrence of strong earthquakes in Himalayan arc region. Proc Indian Acad Sci Earth Planet Sci 101:369-385

Bhattarai M, Adhikari LB, Gautam UP, Laurendeau A, Labonne C, Hoste-Colomer R, Sèbe O, Hernandez B (2015) Overview of the large 25 April 2015 Gorkha, Nepal, earthquake from accelerometric perspectives. Seismol Res Lett 86:1540-1548

Bus Z, Szeidovitz G, Vaccari F (2000) Synthetic seismograms based deterministic seismic zoning for the Hungarian part of the Pannonian Basin. Pure Appl Geophys 157:205-220

Cancani A (1904) Sur l'emploi d'une double echelle seismique des intesites, empirique et absolue. G Beitr 2:281-283

Castaños H, Lomnitz C (2002) PSHA: is it science? Eng Geol 66: 315-317

Chandra U (1977) Earthquakes of Peninsular India-a seismotectonic study. Bull Seismol Soc Am 67:1387-1413

Chandra U (1978) Seismicity, earthquake mechanics and tectonics along the Himalayan mountain range and vicinity. Phys Earth Planet Inter 16:109-131

D’Amico V, Albarello D, Mantovani E (1999) A distribution-free analysis of magnitude-intensity relationships: an application to the Mediterranean region. Physics and Chemistry of the Earth, Part A: Solid Earth and Geodesy 24 (6):517-521

Dixit AM, Ringler AT, Sumy DF, Cochran ES, Hough SE, Martin SS, Gibbons S, Luetgert JH, Galetzk J, Shrestha SN, Rajaure S, McNamara DE (2015) Strong-motion observations of the M 7.8 Gorkha, Nepal, earthquake sequence and development of the N-SHAKE strong-motion network. Seismol Res Lett 86:1533-1539

Doglioni C, Carminati E, Petricca P, Riguzzi F (2015) Normal fault earthquakes or graviquakes. Sci Rep 5. doi:10.1038 /srep 12110

EC8 (1993) Structures in seismic regions-design-part 1. General and building, Doc C250/SC8/ N57A

El-Sayed A, Vaccari F, Panza GF (2001) Deterministic seismic hazard in Egypt. Geophys J Int 144:555-567 ISSN: 0956$540 \mathrm{X}$

Fasan M, Magrin A, Amadio C, Romanelli F, Vaccari F, Panza GF (2016) A seismological and engineering perspective on the 2016 Central Italy earthquakes. International Journal of Earthquake and Impact Engineering 1(4):395-420

Fitch TJ (1970) Earthquake mechanism in the Himalayan, Burmese and Andaman regions and the continental tectonics in Central Asia. J Geophys Res 75:2699-2709

Galetzka J, Melgar D, Genrich JF, Geng J, Owen S, Lindsey EO, Xu X, Bock Y, Avouac J-P, Adhikari LB, Upreti BN, PrattSitaula B, Bhattarai TN, Sitaula BP, Moore A, Hudnut KW, Szeliga W, Normandeau J, Fend M, Flouzat M, Bollinger L, Shrestha P, Koirala B, Gautam U, Bhatterai M, Gupta R, Kandel T, Timsina C, Sapkota SN, Rajaure S, Maharjan N
(2015) Slip pulse and resonance of the Kathmandu basin during the 2015 Gorkha earthquake, Nepal. Science 349: $1091-1095$

Gelfand IM, Guberman SI, Izvekova ML, Keilis-Borok VI, Ranzman EJA (1972) Criteria of high seismicity, determined by pattern recognition. Tectonophysics 13:415-422

Gelfand IM, Guberman SI, Keilis-Borok VI, Knopoff L, Press F, Ranzman EYA, Rotwain IM, Sadovsky AM (1976) Pattern recognition applied to earthquake epicenters in California. Phys Earth Planet Inter 11:227-283

Gorshkov A, Kossobokov V, Soloviev A (2003) Recognition of earthquake-prone areas. In: Keilis-Borok V, Soloviev A (eds) Nonlinear dynamics of the lithosphere and earthquake prediction. Springer, Heidelberg, pp 239-310

Gorshkov A, Parvez IA, Novikova O (2012) Recognition of earthquake-prone areas in the Himalaya: validity of the results. Int J Geophys. doi:10.1155/2012/419143

Gung Y, Romanowicz B (2004) Q tomography of the upper mantle using three component long period waveforms. Geophys $\mathrm{J}$ Int 157:813-830

Gusev AA (1983) Descriptive statistical model of earthquake source radiation and its application to an estimation of short-period strong motion. Geophys J R Astron Soc 74: 787-808

Hough SE (2015) Introduction to the focus section on the 2015 Gorkha, Nepal, earthquake. Seismol Res Lett 86:1502-1505

Julià J, Jagadeesh S, Rai SS, Owens TJ (2009) Deep crustal structure of the Indian shield from joint inversion of $\mathrm{P}$ wave receiver functions and Rayleigh wave group velocities: implications for Precambrian crustal evolution. J Geophys Res. doi:10.1029/2008JB006261

Kanamori H (1977) The energy release in great earthquakes. J Geophys Res 82:2981-2987

Keilis-Borok VI, Soloviev A (2003) Nonlinear dynamics of the lithosphere and earthquake prediction. Springer-Verlag, Berlin-Heidelberg

Klügel JU (2007) Error inflation in probabilistic seismic hazard analysis. Eng Geol 90:186-192

Lliboutry L (2000) Quantitative geophysics and geology. Springer, Berlin

Magrin A, Parvez IA, Vaccari F, Peresan A, Rastogi BK, Cozzini S, Bisignano D, Romanelli F, Ashish, Choundry P, Roy KS, Mir RR, Panza GF (2016) Neo-deterministic definition of seismic and tsunami hazard scenarios for the Territory of Gujarat (India). In: Earthquakes and their impact on society, pp 193-212. Springer International Publishing

Mandal P (2006) Sedimentary and crustal structure beneath Kachchh and Saurashtra regions, Gujarat, India. Phys Earth Planet Inter 115:286-299

Markušić S, Suhadolc P, Herak M, Vaccari F (2000) A contribution to seismic hazard in Croatia from deterministic modelling. Pure Appl Geophys 157:185-204

Martin SS, Szeliga W (2010) A catalog of felt intensity data for 570 earthquakes in India from 1636 to 2009 . Bull Seismol Soc Am 100:62-569

Martin SS, Hough SE, Hung C (2015) Ground motions from the 2015 Mw 7.8 Gorkha, Nepal, earthquake constrained by a detailed assessment of macroseismic data. Seismol Res Lett 86:1524-1532

Medvedev SV (1977) Seismic intensity scale MSK-76. Publ Inst Geophys Pol Acad Sc 117:95-102 
Mitchell BJ, Cong L, Ekstrom G (2008) A continent-wide map of $1-\mathrm{Hz} \mathrm{Lg}$ coda Q variation across Eurasia and its relation to lithospheric evolution. J Geophys Res. doi:10.1029/2007 JB005065

Mitra S, Priestley K, Bhattacharya AK, Gaur VK (2005) Crustal structure and earthquake focal depths beneath northeastern India and southern Tibet. Geophys J Int 160:227-248. doi:10.1111/j.1365- 246X.2004.02470.x

Mitra S, Kainkaryam SM, Padhi A, Rai SS, Bhattacharya SN (2011) The Himalayan foreland basin crust and upper mantle. Phys Earth Planet Inter 184:34-40

Molnar P, Fitch TJ, Wu-Francis T (1973) Fault plane solutions of shallow earthquakes and contemporary tectonics in Asia. Earth Planet Sci Lett 19:101-112

Murty ASN, Sain K, Rajendra Prasad B (2008) Velocity structure of the West-Bengal Sedimentary Basin, India along the Palashi-Kandi profile using a travel-time inversion of wideangle seismic data and gravity modeling - an update. Pure Appl Geophys 165:1733-1750. doi:10.1007/s00024-0080398-5

Panza GF, Vaccari F, Costa G, Suhadolc P, Fäh D (1996) Seismic input modelling for zoning and microzoning. Earthquake Spectra 12:529-566

Panza GF, Vaccari F, Romanelli F (1999) Deterministic seismic hazard assessment. In: Wenzel F et al (eds) Vrancea earthquakes. Tectonic and risk mitigation. Kluwer, Dordrecht, pp 269-286

Panza GF, Romanelli F, Vaccari F (2001) Seismic wave propagation in laterally heterogeneous anelastic media: theory and application to seismic zonation. Advances in Geophysics 43: 1-95, eds Dmowska, R. \& Saltzman, B., Academic, San Diego

Panza GF, Alvarez L, Aoudia A, Ayadi A, Benhallou H, Benouar D, Yun-Tai C, Cioflan C, Zhifeng D, El-Sayed A, Garcia J, Garofalo B, Gorshkov A, Gribovszki K, Harbi A, Hatzidimitriou P, Herak M, Kouteva M, Kuznetzov I, Lokmer I, Maouche S, Marmureanu G, Matova M, Natale M, Nunziata C, Parvez I, Paskaleva I, Pico R, Radulian M, Romanelli F, Soloviev A, Suhadolc P, Triantafyllidis P, Vaccari F (2002) Realistic modeling of seismic input for megacities and large urban areas (the UNESCO/IUGS/ IGCP project 414). Episodes 25:160-184

Panza GF, Romanelli F, Vaccari F, Decanini L, Mollaioli F (2003) Seismic ground motion modeling and damage earthquake scenarios, a bridge between seismologists and seismic engineers. OECD Workshop on the Relations between Seismological DATA and Seismic Engineering, Istanbul, 16-18 October 2002, NEA/CSNI/R (2003) 18:241-266

Panza GF, Irikura K, Kouteva M, Peresan A, Wang Z, Saragoni R (2011) Advanced seismic hazard assessment. Pure Appl Geophys Topical Volume. ISBN 978-3-0348-0039-6 and ISBN: 978-3-0348-0091-4

Panza GF, La Mura C, Peresan A, Romanelli F, Vaccari F (2012) Seismic hazard scenarios as preventive tools for a disaster resilient society. Adv Geophys 53:93-165 ISSN: 0065-2687

Panza GF, Peresan A, La Mura C (2013) Seismic hazard and strong ground motion: an operational neo-deterministic approach from national to local scale. Geophysics and Geochemistry, [Eds.UNESCO-EOLSS Joint Committee]. Encyclopedia of Life Support Systems (EOLSS), developed under the auspices of the UNESCO, Eolss Publishers, Oxford
Panza GF, Kossobokov V, Peresan A, Nekrasova A (2014) Why are the standard probabilistic methods of estimating seismic hazard and risks too often wrong. Earthq Haz Risk Disasters. doi:10.1016/B978-0-12-394848-9.00012-2

Parvez IA, Gusev AA, Panza GF, Petukhin AG (2001) Preliminary determination of the interdependence among strong motion amplitude, earthquake magnitude and hypocentral distance for the Himalayan region. Geophys J Int 144:577-596

Parvez IA, Vaccari F, Panza GF (2003) A deterministic seismic hazard map of India and adjacent areas. Geophys J Int 155: 489-508

Parvez IA, Romanelli F, Panza GF (2011) Long period ground motion at bedrock level in Delhi city from Himalayan earthquake scenarios. Pure Appl Geophys 168:409-477

Pavlov VM (2009) Matrix impedance in the problem of the calculation of synthetic seismograms for a layeredhomogeneous isotropic elastic medium. Izv Phys Solid Earth 45:850-860

Peresan A, Panza GF (2012) Improving earthquake hazard assessment in Italy: an alternative to "Texas sharpshooting". EOS Transaction. Am Geophys Union 93(51):538

Prasad ASSSRS, Sarkar D, Reddy PR (2002) Identification and usage of multiples in crustal seismics: an application in the Bengal Basin, India. Curr Sci 82:1033-1037

Ravi Kumar M, Mohan G (2005) Mantle discontinuities beneath the Deccan volcanic province. Earth Planet Sci Lett 237:252263

Ravi Kumar M, Saul J, Sarkar D, Kind R, Shukla AK (2001) Crustal structure of Indian Shield: new constraints from teleseismic receiver function. Geophys Res Lett 28:13391342

Soloviev AA, Gvishiani AD, Gorshkov AI, Dobrovolsky MN, Novikova OV (2014) Recognition of earthquake-prone areas: methodology and analysis of the results. Izv Phys Solid Earth 50:151-168

Srinagesh D, Singh SK, Chadha RK, Paul A, Suresh G, Ordaz M, Dattatrayam RS (2011) Amplification of seismic waves in the Central Indo-Gangetic Basin, India. Bull Seismol Soc Am 101:2231-2242. doi:10.1785/0120100327

Tewari HC, Surya Prakasa Rao G, Rajendra Prasad B (2009) Uplifted crust in parts of western India. J Geol Soc India 73:479-488

Vaccari F, Tadili B, El Quadi A, Ramdani M, Ait Brahim M, Limouri M (2001) Deterministic seismic hazard assessment for North Morocco. JSEE 3:1-12

Wang Z (2011) Seismic hazard assessment: issues and alternatives. Pure Appl Geophys 168:11-25. doi:10.1007/s00024-0100148-3

Zhang Z, Teng J, Romanelli F, Braitenberg C, Ding Z, Zhang X, Fang L, Zhang S, Wu J, Deng Y, Ma T, Sun R, Panza GF (2014) Geophysical constraints on the link between cratonization and orogeny: evidence from the Tibetan Plateau and the North China Craton. Earth Sci Rev 130:1-48

Živčić M, Suhadolc P, Vaccari F (2000) Seismic zonation of Slovenia based on deterministic hazard computation. Pure Appl Geophys 157:171-184

Zuccolo E, Vaccari F, Peresan A, Panza GF (2011) Neodeterministic and probabilistic seismic hazard assessments: a comparison over the Italian territory. Pure Appl Geophys 168:69-83 